adopted in the Goodenough Report (p. 133) which suggested that biology should be taught along with anatomy, and only to a lesser extent with physiology. Such a suggestion could only result from the complete failure to appreciate what biology is and why it is taught to medical students.

To conclude: the biology course for medical students requires modification. It must clearly set out the fundamentals of biology, including the laws relating to living matter and the study of heredity. The student will follow certain branches of the disciplines of zoology and botany and thus obtain experience of the methods of the biological sciences. He will learn to make observations both at the biological level and on living objects. Both plant and animal kingdoms will be surveyed; advantage will be taken to direct attention to the animals and plants directly affecting man, particularly those which attack or parasitize him. Man's own position in the realm of living things will be made clear, and the student will learn to appreciate plants and animals as 'going concerns' from the moment of syngamy until the death of the individual. When we have such a course it may be possible to begin to dispel the illusion that 'biology' and 'the frog' are synonymous.

1 Committee on the Curriculum and Examinations for Secondary Schools in England and Wales (Norwood Report).

${ }^{2}$ Inter-departmental Committee on Medical Schools (Goodenough Committee) (1944).

${ }^{3}$ The Training of a Doctor : Report of the Medical Curriculum Committee of the British Medical Association, London, 1948.

4 Abercrombie, M., and Johnson, M. L., Brit. Med. J., 2, 262 (1945). $\|$

\section{NEW TRIODE FOR CENTIMETRE WAVES}

$\mathrm{T}$ HE rapid and spectacular development of tele. vision in the Un noctstates has directed attention to several predleds associated with the use of radio relay systems rof centimetric wave-lengths, and the Bell detwone Laboratories are actively engaged in thesation of these problems. The radio television ref system which is already working between New York and Boston operates on a frequency in the region of 4,000 Mc./s., and uses amplifiers incorporating velocity-modulated tubes. Experience has shown that while such tubes are satisfactory for their present purpose, they suffer from a number of limitations which render them unsuitable for longdistance relay work such as will be required to reach from coast to coast across America. As a result, consideration has been given to the possibilities of developing a triode valve which will have an effective amplification at the above frequencies, and the successful production of a suitable valve is described in an article by J. A. Morton in the May number of Bell Laboratories Record (27, 166).

This microwave triode, designated as BTL 1553, is an improved planar triode in which by careful design and very skilful mechanical construction the gridcathode spacing has been reduced to less than the thickness of the oxide coating used on the eathodes of older types of triodes for very high frequencies. The cathode is a nickel core mounted in a ring of low-loss ceramic in such a manner that the nickel and ceramic surfaces may be ground flat and coplanar to a high degree of precision. An oxide coating, 0.5 mil thick, is sprayed on to the upper surface of the cathode. The grid wires, $0 \cdot 3$ mil in diameter, are wound at 1,000 turns per inch on $a_{*}$ molybdenum frame that has been previously goldsputtered; this grid frame is separated from the cathode ceramic supporting-ring by a thin copper skin, and the whole riveted together with three synthetic sapphire rods. The anode is separately supported with a spacing of 10 mils from the grid.

Production yields of such triodes have been successfully obtained under carefully controlled conditions, and show that they have advantages over the velocity-modulated tubes in giving a greater gain for a larger band-width and for a lower operating voltage. The low-frequency characteristics of the triode show that working at an anode voltage of 250 , and current of 25 milliamp., the transconductance of the tube is about $2,000 \mu$ mhos per milliamp., while at lower operating currents this figure is greater. A wave-guide amplifier circuit for this triode has been developed and incorporates resonant cavities and coupling windows such that the amplifier may be tuned and matched to the wave-guide over a frequency range $3,700-4,200 \mathrm{Mc}$. $\mathrm{s}$. In this way, and with a bandwidth of 120-170 Mc./s., a gain of 7-10 db. can be obtained. The type 1553 triode also works well as a modulator valve and as a harmonic generator. These properties make the valve very suitable for long-distance radio relay systems, in that they make possible improved repeaters which do not require excessively high voltages, and which, for about half the power consumption, provide much better transmission characteristics than have hitherto been available.

The production of this type of valve provides an excellent illustration of the manner in which, when the need arises, old ideas may sometimes be successfully resurrected and, in conjunction with new techniques and materials, made to yield revolutionary results.

\section{FOOD AND WORLD POPULATION}

TN August $1948^{\circ}$ delegates from twenty different 1 countries roturat Cheltenham to consider the problem ofyising populations throughout the world and the resources of food, clothing and housing arpil lloke to meet their needs. The Congress was presided over by Lord Horder, and after papers had been presented by speakers of international authority, deliberations proceeded by means of four discussion groups which considered: (1) current research in problems of contraception; (2) research in subfertility and sperm resistance; (3) international liaison, including the present situation in Germany ; and (4) sex education and marriage guidance. ("Proceedings of the International Congress on Population and World Resources in Relation to the Family." H. K. Lewis. 10s. 6d. net.)

The first discussion group considered the present world food crisis, and since this is due, in part, to the growing pressure of the population on food and other resources, the Congress agreed to invite all national Governments and appropriate international organisations to make every effort to initiate positive population policies in accordance with the situation in their respective areas, and to make available knowledge of and advice on family planning techniques to the peoples of the world.

Governments were also encouraged to take action to encourage and finance research into the basic problems of human fertility and infertility. 